\title{
Perioperative rehabilitation in operation for lung cancer (PROLUCA) - rationale and design
}

\author{
Maja S Sommer ${ }^{1 *}$, Karen Trier ${ }^{1}$, Jette Vibe-Petersen ${ }^{1}$, Malene Missel ${ }^{2}$, Merete Christensen ${ }^{2}$, Klaus R Larsen ${ }^{3}$, \\ Seppo W Langer ${ }^{4}$, Carsten Hendriksen ${ }^{5}$, Paul Clementsen ${ }^{6}$, Jesper $\mathrm{H}^{\text {Pedersen }}{ }^{2}$ and Henning Langberg ${ }^{7}$
}

\begin{abstract}
Background: The purpose of the PROLUCA study is to investigate the efficacy of preoperative and early postoperative rehabilitation in a non-hospital setting in patients with operable lung cancer with special focus on exercise.
\end{abstract}

Methods: Using a 2x2 factorial design with continuous effect endpoint (Maximal Oxygen Uptake $\left(\mathrm{VO}_{2}\right.$ peak)), 380 patients with non-small cell lung cancer (NSCLC) stage I-Illa referred for surgical resection will be randomly assigned to one of four groups: (1) preoperative and early postoperative rehabilitation (starting two weeks after surgery); (2) preoperative and late postoperative rehabilitation (starting six weeks after surgery); (3) early postoperative rehabilitation alone; (4) today's standard care which is postoperative rehabilitation initiated six weeks after surgery. The preoperative rehabilitation program consists of an individually designed, 30-minute home-based exercise program performed daily. The postoperative rehabilitation program consists of a supervised group exercise program comprising cardiovascular and resistance training two-hour weekly for 12 weeks combined with individual counseling. The primary study endpoint is $\mathrm{VO}_{2}$ peak and secondary endpoints include: Six-minute walk distance (6MWD), one-repetition-maximum (1RM), pulmonary function, patient-reported outcomes (PROs) on health-related quality of life (HRQOL), symptoms and side effects of the cancer disease and the treatment of the disease, anxiety, depression, wellbeing, lifestyle, hospitalization time, sick leave, work status, postoperative complications (up to 30 days after surgery) and survival. Endpoints will be assessed at baseline, the day before surgery, pre-intervention, post-intervention, six months after surgery and one year after surgery.

Discussion: The results of the PROLUCA study may potentially contribute to the identification of the optimal perioperative rehabilitation for operable lung cancer patients focusing on exercise initiated immediately after diagnosis and rehabilitation shortly after surgery.

Trial Registration: NCT01893580

Keywords: Cancer, Rehabilitation, Exercise, Lung cancer, NSCLC

\section{Background}

Lung cancer is one of the most frequently occurring cancer diagnoses with the highest mortality rate [1]. Lung cancer is divided into Small-Cell Lung Carcinoma (SCLC) and Non-Small Cell Lung Carcinoma (NSCLC). Surgery is at present the primary treatment for NSCLC. According to the Danish Register of Lung Cancer 2011, the 2 -year survival was $62 \%$ and the 5 -year survival $42 \%$

\footnotetext{
* Correspondence: mss@kraeftcenter-kbh.dk

${ }^{1}$ Copenhagen Centre for Cancer and Health, Municipality of Copenhagen, Nørre Allé 45, DK-2200 Copenhagen, Denmark

Full list of author information is available at the end of the article
}

following radical surgery for lung cancer [2]. Modern surgical treatment includes both minimal invasive surgery, e.g. video-assisted thoracoscopic surgery (VATS), and open surgery such as thoracotomy. An increasing proportion of lung cancer patients are operated by VATS technique in both Europe and the US. At Copenhagen University Hospital (Rigshospitalet), more than $60 \%$ of all lung cancers patients are operated by VATS [2].

Improved surgical techniques combined with effective adjuvant chemotherapy have led to a significant survival benefit in individuals with NSCLC $[3,4]$. Postoperative complications are experienced by $25 \%$ of the patients 
with NSCLC [2], and the risk of developing postoperative complications during the first two weeks after surgery has been reported to be dependent on different factors, e.g. preoperative cardiorespiratory capacity, measured as $\mathrm{VO}_{2}$ peak $[1,5]$. The physiological consequences of ageing and inactivity combined with the cancer disease and the treatment of cancer result in a marked reduction in $\mathrm{VO}_{2}$ peak and functional capacity [6-8]. Other factors such as smoking [9], alcohol consumption [10], nutritional status [11] and comorbidity [12] are predictors of postoperative complications. The treatment of NSCLC and other types of cancer is complex and potentially lethal. Accordingly, side effects are now recognized as a subject of major clinical importance [13]. The side effects may comprise physical and psychological as well as social distress with symptoms such as reduced cardiorespiratory capacity, paresthesia, post-thoracotomy pain syndrome, fatigue, anxiety, and depression [14-16]. The late side effects are long-lasting or even chronic and may result in restrictions in activity of daily living and reduced quality of life [5,17-23].

A Cochrane systematic review from 2012 indicates that exercise in patients with a variety of cancer diagnoses may have beneficial effects on HRQoL [24]. This is supported by a Danish randomized controlled trial with 269 cancer patients (different diagnoses) according to which patients receiving chemotherapy tolerate intensive physical exercise and experience reduced fatigue, depression, and nausea [25]. In general, rehabilitation in cancer patients based on physical exercise perioperatively has been shown to increase HRQoL and physical activity, and at the same time reduce the side effects of the treatment [24,26-33]. There is consistent evidence from 27 observational studies that physical activity is associated with reduced all-cause, breast cancer-specific, and colon cancer-specific mortality [34].

Clinical studies of preoperative physical exercise in patients with operable NSCLC are sparse. However, a recent prospective feasibility study on 25 patients with NSCLC reports that the patients tolerate 30 minutes of preoperative intensive cardiovascular exercise 5 times/ week. The study finds that exercise significantly improves $\mathrm{VO}_{2}$ peak and 6MWD [35]. Two other studies indicate that rehabilitation including preoperative exercise can improve physical and psychological outcome in patients with NSCLC $[36,37]$.

The effect of postoperative physical exercise in patients with lung cancer has been investigated briefly. The studies differ in type of intervention, dose and timing of intervention, and the research is primarily based on case studies and studies with few and heterogeneous participants [36]. Two non-randomized feasibility studies observed that supervised moderate to high intensity cardiovascular exercise initiated four weeks after surgery is safe and feasible for operable lung cancer patients. The intervention consisted of three weekly cycling sessions for a period of 14 weeks, and participation was associated with a significantly improved HRQoL $[38,39]$.

In a prospective study of 45 lung cancer patients, exercise on ergometer bikes 30 minutes daily, initiated two weeks after end of cancer treatment (including both surgery and chemotherapy), was reported to result in a pronounced improvement in exercise capacity and functional status [40]. The results are confirmed by other studies $[41,42]$. Another randomized study of 53 lobectomized lung cancer patients showed retention of muscle strength in the intervention group in which the patients participated in mobilization and strength exercise twice daily during admission followed by a 12-week long home exercise program. HRQoL (EORTC questionnaire) and physical capacity (measured by 6MWD) were unchanged [43]. Overall, these studies indicated that postoperative exercise may have a positive effect on physical capacity and HRQoL in NSCLC. A systematic review from 2011 concluded that pre- and postoperative exercise is safe and feasible for NSCLC patients and associated with a positive effect on physical capacity and, to some extent, HRQoL [26]. However, the main part of the studies quoted in the review are small case series and the only randomized study in the review observes no difference between the intervention and the control group [26]. In summary, several studies indicate that postoperative exercise of NSCLC patients is safe and associated with improvement of fitness and self-reported outcome such as HRQoL and fatigue $[27,44]$. Positive effects of perioperative exercise interventions are more pronounced with moderate- to vigorousintensity versus mild-intensity exercise programs. More research is required to fully understand the potential effect of exercise over time and to determine essential attributes of exercise (mode, intensity, frequency, duration, and timing) by cancer type and cancer treatment [24].

To our knowledge the present Perioperative Rehabilitation in Operation for LUng CAncer (PROLUCA) study is the first study to investigate the clinical effects of pre- and early postoperative rehabilitation in NSCLC patients. In PROLUCA a randomized clinical trial, the efficacy of preand early postoperative rehabilitation is compared with the effect of rehabilitation initiated six weeks after surgery (usual care) in a non-hospital setting.

The aim of PROLUCA is to identify the optimal timing of exercise to improve $\mathrm{VO}_{2}$ peak in postoperative NSCLC patients. The specific aims are: (1) comparison of combined preoperative home-based exercise with postoperative exercise regarding $\mathrm{VO}_{2}$ peak and patientreported outcomes (PROs), (2) comparison of early postoperative exercise (initiated as early as two weeks after surgery) with usual care regarding $\mathrm{VO}_{2}$ peak and PROs. 


\section{Methods}

\section{Participants and settings}

The study will recruit and randomize 380 patients (95 patients/study arm) with histologically or cytologically confirmed NSCLC, stage I-IIIa (TNM classification v. 7 [45]) or strong substantiated suspicion of NSCLC, referred for surgery. All subjects are assigned for curative lung cancer surgery at Department of Cardiothoracic Surgery, Copenhagen University Hospital (Rigshospitalet). The inclusion and exclusion criteria are described in Table 1: Subject Eligibility Criteria in the PROLUCA Trial.

\section{Procedure}

The study is conducted in accordance with the CONSORT (Consolidated Standards of Reporting Trials) statement for non-pharmacologic interventions and the Helsinki Declaration [49]. Informed consent is obtained from all participants prior to initiation of any study procedures. The study is approved by The Danish National Committee

Table 1 Subject eligibility criteria in the PROLUCA trial

\begin{tabular}{l} 
Inclusion criteria \\
\hline All subjects are assigned for \\
curative lung cancer surgery at \\
Department of Cardiothoracic \\
Surgery RT at Copenhagen \\
University Hospital (Rigshospitalet). \\
At least 18 years old. \\
Performance status 0-2 (WHO) \\
[46]. \\
Living in the City of Copenhagen \\
or surrounding Municipalities.
\end{tabular}
or surrounding Municipalities.

Ability to read and understand Danish.

Approval by primary surgeon.

\section{Exclusion criteria}

Presence of metastatic disease or surgical inoperability.

Diagnosis of Lung Cancer not verified by histological diagnosis.

Cardiac disease [6,47].

Contraindications to maximal exercise testing as recommended by the American Thoracic Society and exercise testing guidelines for cancer patients [48].
Screened for eligibility criteria at Bispebjerg University Hospital and Gentofte Hospital.

Capable of participating in the described tests and intervention.

Reside within driving distance of Copenhagen Centre for Cancer and Health and capable of managing transportation as necessitated by the clinic-based assessments and supervised exercise interventions.

To examine for any contraindication in participating in physical exercise.

Decompensated heart failure, severe aortic stenosis, uncontrolled arrhythmia, acute coronary syndrome. on Health Research Ethics (H-3-2012-028) and the Danish Data Protection Agency (2007-58-0015).

The study flow is presented in Figure 1 Study Flow PROLUCA. Using a 4-arm, randomized design, potential subjects will be identified and screened for eligibility and informed about PROLUCA by the study research coordinators at the involved hospitals (Bispebjerg University Hospital and Gentofte Hospital). After referral to intended curative lung cancer surgery at Copenhagen University Hospital (Rigshospitalet), the subjects are contacted by telephone and provided with a review of the study. If the subjects accept to participate, the baseline assessment is performed at Copenhagen Centre for Cancer and Health. At baseline the following assessments are performed: (1) PROs described in Table 2 Data Assessment Schedule in the PROLUCA Trial, (2) anthropometric data, (3) 6MWD, (4) muscle strength (1RM in chest- and legpress machines), (5) pulmonary function test, and (6) cardiopulmonary exercise test $\left(\mathrm{VO}_{2}\right.$ peak). All baseline assessments will be completed as close to time of diagnosis as possible and repeated the day before surgery, pre-intervention (6MWD, pulmonary function, FACT-L), post-intervention, and at follow-up six months and one year after surgery.

\section{Group allocation (Randomization)}

Following the successful completion of baseline assessments, participants will be randomly allocated, on an individual basis, to one of the four exercise intervention groups:

Group 1: Preoperative home-based exercise and postoperative rehabilitation initiated as early as two weeks after surgery.

Group 2: Preoperative home-based exercise and postoperative rehabilitation initiated six weeks after surgery.

Group 3: Postoperative rehabilitation initiated as early as two weeks after surgery.

Group 4: Postoperative rehabilitation initiated six weeks after surgery (Usual practice as control group).

The random allocation sequences will be concealed from all study personnel and performed by Copenhagen Trial Unit, Centre for Clinical Intervention Research. A permuted block design with allocation weight of 1:1:1:1 will be used to generate the treatment assignments. Randomly allocated participants will remain in the same group for the entire duration of the intervention, as expressed in Figure 2 PROLUCA Study Timeline. To ensure similarity of randomized groups at baseline, patient randomization will be stratified based on type of surgery, VATS versus thoracotomy surgery.

\section{Blinding}

It is not possible to blind the participants to their actual treatment allocation, since participants are aware whether 


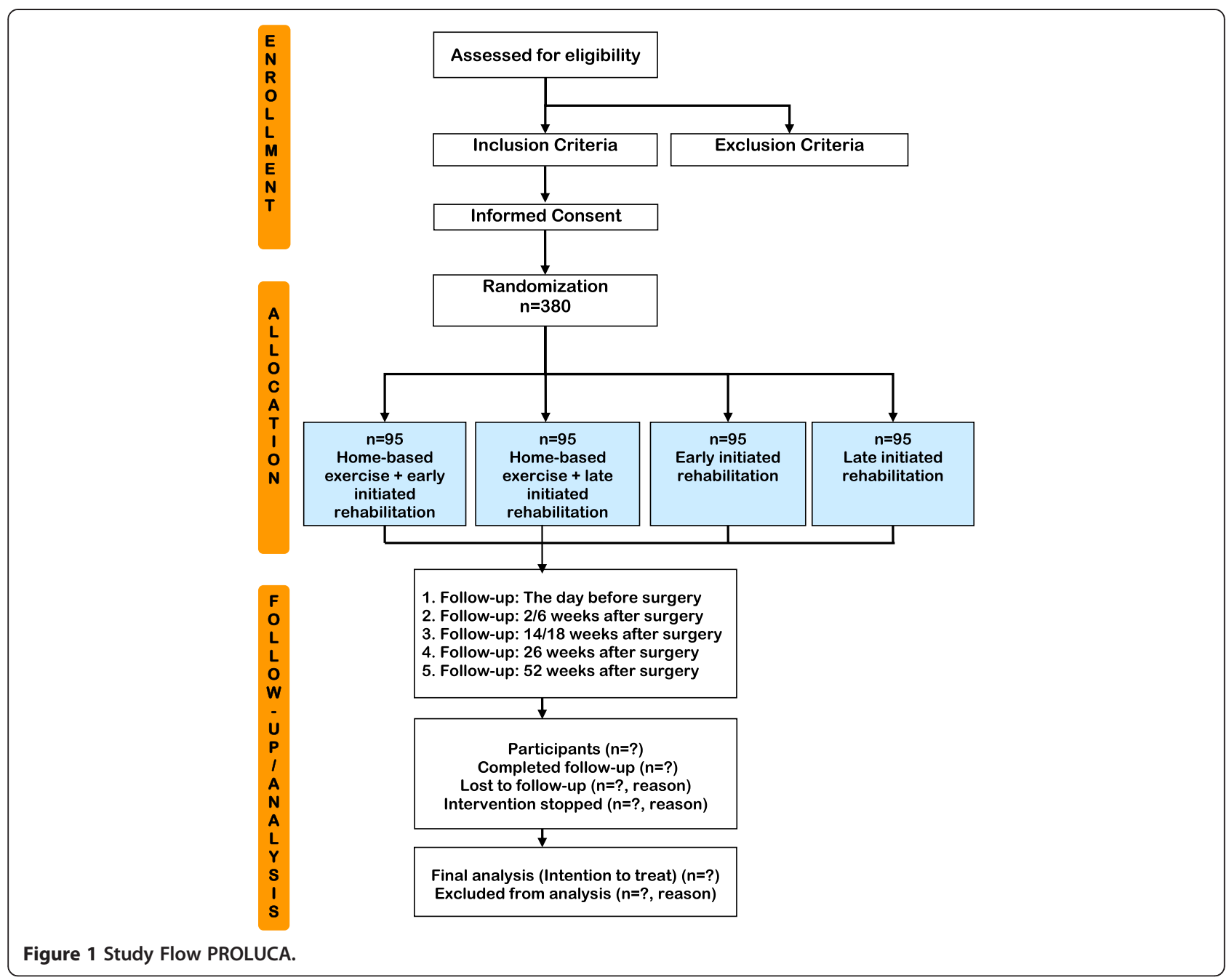

they initiate preoperative exercise and whether their postoperative exercise starts two or six weeks after surgery. All study personnel collecting data and doing the statistical analyses of the data are, however, blinded to the patient allocation, and the patients are strictly informed not to reveal their group allocation to the test personnel.

\section{Exercise training protocols (General considerations) Preoperative exercise}

The home-based exercise program is individually designed for each of the participants randomized to a preoperative intervention. The ultimate goal of the preoperative homebased exercise program is to ensure that the patients perform cardiovascular exercise of moderate-vigorous intensity ( $60-80 \%$ of maximum heart rate (HRmax)) for at least 30 minutes every day until surgery. The preoperative period varies in length and the intention is not to exceed 14 days. The preoperative exercise is monitored by a heart rate sensor (Polar Team 2 System, with off-line transmitters) and an exercise diary logbook.

\section{Postoperative rehabilitation}

The postoperative intervention consists of a supervised 12-week rehabilitation program containing 24 groupbased exercise sessions, three individual counseling sessions, and three group-based lessons in health-promoting behavior. If the participants have special needs in terms of smoking cessation, nutritional counseling or patient education, this is offered too.

The postoperative physical exercise consists of an individually prepared supervised strength exercise and a group-based cardiovascular exercise twice a week (60 minutes/session) on non-consecutive days for 12 weeks, a total of 24 sessions, containing the following elements:

Warm-up (five minutes) and cardiovascular exercise (25 minutes) on ergometer bike (BODY BIKE Classic Supreme $\odot)$, individually prepared strength exercise (25 minutes) carried out using five machines (Technogym $\left.^{\mathrm{TM}}\right)$, leg press, chest press, leg extension, pull to chest, pull-down (upper body). The practical aim of strength exercise is to complete three series of 5-12 
Table 2 Data assessment schedule in the PROLUCA trial

\begin{tabular}{|c|c|c|c|c|c|c|}
\hline & Baseline $^{a}$ & Flw-up ${ }^{b}$ & Flw-up ${ }^{c}$ & Flw-up ${ }^{d}$ & Flw-up ${ }^{e}$ & Flw-up \\
\hline Anthropometric data and cancer disease & $x$ & $x$ & & $x$ & $x$ & $x$ \\
\hline \multicolumn{7}{|c|}{ Physiological measurements } \\
\hline Cardiorespiratory capacity $\left(\mathrm{VO}_{2}\right.$ peak) & $x$ & $x$ & & $x$ & $x$ & $x$ \\
\hline Six- minute walk distance (6MWD) & $x$ & $x$ & $x$ & $x$ & $x$ & $x$ \\
\hline One-repetition-maximum (1RM) & $x$ & $x$ & & $x$ & $x$ & $x$ \\
\hline Heart rate $(\mathrm{HR})$, Blood pressure (BP) & $x$ & $x$ & & $x$ & $x$ & $x$ \\
\hline Spirometric $\left(\mathrm{FEV}_{1} / \mathrm{FEV}_{1} \%\right)$ & $x$ & $x$ & & $x$ & $x$ & $x$ \\
\hline \multicolumn{7}{|c|}{ Patient-reported outcome } \\
\hline Health-related quality of life (EORTC QLQ-C30, FACT-L) & $x$ & $x$ & FACT-L & $x$ & $x$ & $x$ \\
\hline Symptoms and side effects (EORTC-LC13) & $x$ & $x$ & & $X$ & $x$ & $x$ \\
\hline Anxiety and depression (HADS) & $x$ & $x$ & & $x$ & $x$ & $x$ \\
\hline Well-being (SF-36) & $x$ & $x$ & & $x$ & $x$ & $x$ \\
\hline Distress thermometer & $x$ & $x$ & & $x$ & $x$ & $x$ \\
\hline Lifestyle & $x$ & $x$ & & $x$ & $x$ & $x$ \\
\hline Sickness absence and work status & $x$ & $x$ & & $x$ & $x$ & $x$ \\
\hline Social support (MSPSS) & $x$ & $x$ & & $x$ & $x$ & $x$ \\
\hline \multicolumn{7}{|c|}{ Other measurements } \\
\hline Perioperative complications & X (30 days) & X (30 days) & & & & \\
\hline Duration of hospitalization & X (30 days) & X (30 days) & & & & \\
\hline Survival Histological diagnosis and TNM staging & & & & & & $x$ \\
\hline
\end{tabular}

${ }^{\mathrm{a}}$ Baseline (0 week).

${ }^{\mathrm{b}} \mathrm{Flw}$-up (Follow-up): Preoperation (the day before surgery).

cFlw-up (Follow-up): Pre-intervention (2/6 weeks after surgery).

${ }^{d}$ Flw-up (Follow-up): Post-intervention (14/18 weeks after surgery).

eFlw-up (Follow-up): Six months after surgery.

${ }^{f}$ Flw-up (Follow-up): One year after surgery.

sets. Trained physiotherapists and cancer nurse specialists supervise the training program following the recommended principles [50]. All exercise sessions will include supervised breathing exercises combined with stretching and relaxation techniques (five minutes). All the cardiorespiratory exercise is designed such that participants begin exercising at a low intensity ( 50\%$60 \%$ of individually determined HRmax) which is subsequently increased to more moderate to vigorous intensity ( $70 \%-80 \%$ of individually determined HRmax).
The ultimate goal for the postoperative exercise is two group-based exercise sessions per week, with a cardiorespiratory intensity for the first four weeks at 50-60\% of individual HRmax. The next eight weeks the intensity increases to moderate-high intensity at $\sim 70-90 \%$ of individually determined HRmax. The heart rate will be monitored continuously throughout the cardiorespiratory exercise using heart rate monitors and software (Polar $\mathrm{Team}^{2}$ Pro $\left.\odot\right)$. All interventions will be individually tailored to each participant and following the principles of

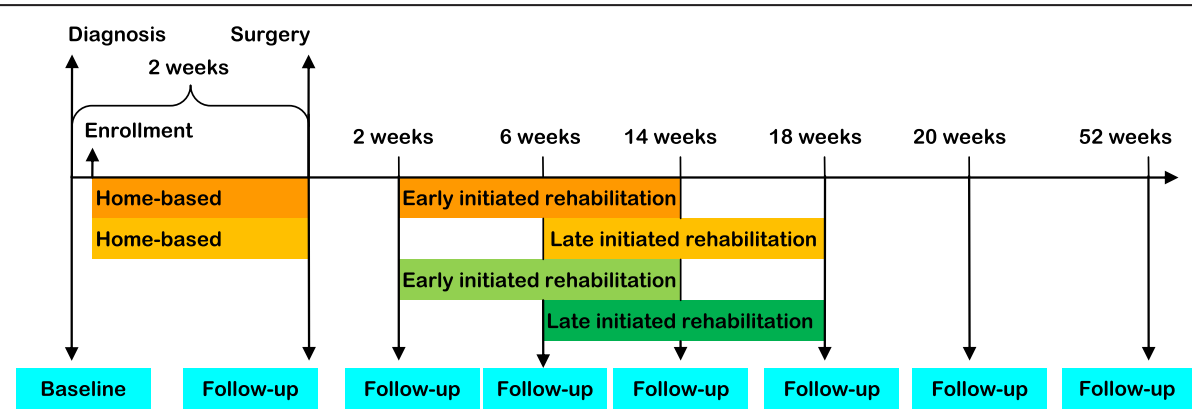

Figure 2 PROLUCA Study Timeline (three intervention groups and one control group). 
aerobic or resistance training prescription guidelines for adults as recommended by the American College of Sports Medicine (ACSM) [50]. The ultimate goal for the strength exercise program is to exercise with an intensity of $\sim 60-80 \%$ of 1 RM two times a week for 12 weeks. To ensure progression every second week, the load is progressively increased and the number of repetitions are reduced starting out at 12 repetitions in three sets progressing to 10 repetitions in three sets to a final of eight repetitions in three sets. The progression is documented in a study exercise log file for registration of the intensity of all sessions along with data on blood pressure prior to exercise.

\section{Adherence Considerations}

To maximize adherence, several strategies will be employed including telephone-based follow-ups. The patients are provided free parking in front of the center and transport expenses are covered. The high degree of scheduling flexibility allows participants to perform test at a convenient time and work around other competing demands such as medical appointments, work, and family commitments.

\section{Study endpoints and assessments Primary endpoint}

$\mathrm{VO}_{2}$ peak is evaluated by an incremental test using an electromagnetically braked cycle ergometer (Lode Corival Ergometer( $)$ ). Inspired and expired gases are analyzed breath-by-breath by a metabolic cart (JAEGER MasterScreen $\mathrm{CPX}($ )). Subjects begin pedaling at seven watts and resistance increases after a predefined 10 watts ramp protocol until exhaustion or a symptom-limited $\mathrm{VO}_{2}$ peak is achieved (pain, dizziness, anxiety etc.). This regimen has previously been demonstrated to be appropriate for measuring $\mathrm{VO}_{2}$ peak in prior studies in patients with ankylosing spondylitis [51]. Other similar $\mathrm{VO}_{2 \text { peak }}$ protocols are found appropriate for measuring $\mathrm{VO}_{2}$ peak in NSCLC $[38,39,52]$.

\section{Secondary endpoints}

Patient-reported outcomes (PROs) PROs will include HRQoL, symptoms and side effects, anxiety and depression, well-being, distress, lifestyle, sickness absence, work status, and social support. HRQoL is assessed using the integrated system of the European Organization for Research and Treatment in Cancer (EORTC) for assessing the HRQoL of cancer patients participating in international clinical trials and devised through collaborative research. The EORTC QLQ-C30 assesses patient symptoms and HRQoL in lung cancer patients [53]. Symptoms and side effects will be assessed using the EORTC-LC13, which is an additional page to the EORTC-QLQ specifically designed to cover a wide range of lung cancer patients varying in disease stage and treatment modality [54]. EORTC measures single items and the scales range in score from 0 to 100. A high scale score represents a higher response level. A high score for a functional scale represents a high/healthy level of functioning and a high score for the global health status/quality of life represents a high HRQoL. However, a high score for a symptom scale/item represents a high level of symptomatology or problems [53,54].

HRQoL will also be assessed using the Functional Assessment of Cancer Therapy - Lung (FACT-L) scale that contains four subscales for physical (7-items), functional (7-items), emotional (6-items), social/family well-being (7-items) plus a lung cancer specific subscale (15-items) which will be summed to obtain the FACT-L score (all 42 items) [55].

General well-being is assessed using the 36-Item Short Form Health Survey (SF-36), standard recall (four weeks). The SF-36 includes eight scales measuring general health with two summary scales; physical and mental component scales [56,57]. To assess psychological well-being, the Hospital Anxiety and Depression Scale (HADS) with 14 items will be administered, designed to measure general anxiety and depression for use in investigations of patients with physical illness [58]. The distress thermometer is a validated measure of distress and consists of a single item, with responses ranging from 0 to 10 [59].

The Multidimensional Scale of Perceived Social support (MSPSS) is a 12-item scale assessing social support. Each item is answered on a seven-point Likert scale, from one: Very strongly disagree, to seven: Very strongly agree. The scale yields three subscale scores, for Family, Friends, and Significant Others, and a Total score, which is confirmed in a confirmatory factor analysis [60]. In other different cancer studies, all the above-mentioned validated instruments were found appropriate and easy to administer $[35,52,59,61]$.

\section{Physiological measurements}

Physiological measurements will include: (1) functional capacity, (2) pulmonary function, (3) cardiovascular $\mathrm{O}_{2}$ delivery, and (4) muscle strength. (1) functional capacity will be measured by a six-minute walking distance (6MWD) test carried out over a pre-measured distance of $22 \mathrm{~m}$ and in accordance with the American Thoracic Society (ATS) statement [62]. The 6MWD test has demonstrated good reliability and validity in patients with chronic obstructive lung disease [63], a patient group with similar symptomatology and pathophysiology. (2) Pulmonary Function will be determined by assessing the Forced Expiratory Volume in one second $\left(\mathrm{FEV}_{1}\right)$, and the $\mathrm{FEV}_{1} \%$ which is the ratio of $\mathrm{FEV}_{1}$ to the Forced Vital Capacity (FVC) using a Triple $\mathrm{V}$ digital volume sensor` connected to JAEGER MasterScreen CPX®. All pulmonary function 
tests will be performed in a standing position and according to the ATS guidelines [48]. (3) Arterial $\mathrm{O}_{2}$ Saturation will be assessed at rest and continuously during exercise using pulse oximetry (Nellcor, OxiMax N-65@), which provides the most accurate non-invasive assessment of blood arterial $\mathrm{O}_{2}$ saturation levels. Muscle strength is measured by 1RM [64] using machines (Technogym ${ }^{\mathrm{Tm}}$ ) that includes leg press (lower extremity) and chest press (pectoral muscles).

\section{Disease-related outcomes}

In all patients lung cancer subtype, stage and extent of surgery will be related to the effect of exercise and rehabilitation interventions.

\section{Tracking and monitoring of adverse events}

Tracking and monitoring of adverse events are assessed as follows: (1) before every intervention- and test-session, all patients will receive face-to-face supervision by a specialized trained cancer nurse discussing any potential negative side effects of the intervention assignment. All injuries and adverse events (e.g., knee pain, back pain) will be recorded as unintended events. In addition, heart rate and blood pressure are recorded prior to every intervention session and repeated if any adverse events should occur during exercise.

\section{Statistical considerations Sample size calculation}

This randomized phase II trial will accrue 380 subjects with operable NSCLC over an accrual period of $\sim 2$ years. The present design consists of four intervention groups of equal size, and it is assumed that no interaction occurs between the groups. With the smallest clinical relevant difference set at $2 \mathrm{mLO}_{2} \cdot \mathrm{kg}^{-1} \cdot \mathrm{min}^{-1}, 95$ participants are required in each group (power: $80 \%$ ), giving a total inclusion of 380 patients.

For each of the primary and secondary endpoints, three separate t-tests will be used to compare each experimental arm to the control arm in mean change across time of the endpoint. For each endpoint, the overall alpha level will be controlled at a two-sided 0.05 by using Holm's procedure [65]. That is, Holm's procedure first ranks the three pvalues from lowest to highest. The first (lowest) p-value has to be less than $0.05 / 3(0.0167)$ to be significant and permit continuation to the other t-tests. The Holm's procedure continues sequentially in this fashion using alpha levels of $0.05 / 2(0.025)$ and $0.05 / 1(0.05)$ for the remaining two t-tests, respectively. Power for this study is defined as the probability that at least one of the three t-tests of the arm effect on $\mathrm{VO}_{2}$ peak is significant; in other words, power is the probability that the first of the 3 ordered t-tests are significant. We assume that change in $\mathrm{VO}_{2}$ peak will have a standard deviation of
$4.0 \mathrm{~mL} \cdot \mathrm{kg}^{-1} \cdot \mathrm{min}^{-1}$ as observed in previous research $[27,36]$. Statistical power depends upon the configuration of mean change in $\mathrm{VO}_{2}$ peak across the 4 arms. Thus, for example, $80 \%$ power is obtained when the mean change in $\mathrm{VO}_{2}$ peak across Arms 1, 2, 3, and 4 is $0.60,0.60,2.10$, and $0.0\left(\mathrm{~mL} \cdot \mathrm{kg}^{-1} \cdot \mathrm{min}^{-1}\right)$, respectively.

\section{Analytic plan}

The intention-to-treat analysis includes all randomized participants in their randomly assigned allocations. The intervention group assignment will not be altered based on the participant's adherence to the randomly allocated study arm. Patients who are lost-to-follow-up are included in the analysis (intention to treat). For the primary analysis, a multiple regression model will be used to assess a change in $\mathrm{VO}_{2}$ peak on study group, the baseline value of the endpoint, and other pertinent baseline variables that may influence change in the study endpoints (e.g., comorbid conditions/medications, self-reported exercise history, age). Data from PROs will be presented as mean, standard deviation (SD), median and inter-quartile range (IQR) and all change scores (value at follow-up minus value at baseline) will be presented with a $95 \%$ confidence interval.

\section{Discussion}

The aim of PROLUCA is to contribute with important knowledge about the efficacy of pre- and early postoperative rehabilitation in patients with NSCLC in a nonhospital setting.

The decision to target newly diagnosed patients with NSCLC was primarily based on the fact that these patients are not often examined in relation to the effect of rehabilitation, although they generally have a good performance status and prognosis after surgery and adjuvant chemotherapy. In consequence, the issue of NSCLC survivorship is becoming an increasingly important aspect of the multidisciplinary care of this patient group and the demands for knowledge correspondingly important.

The need for rehabilitation becomes obvious by the fact that NSCLC patients are subject to a marked decrease in cardiorespiratory capacity due to a combination of age and comorbidity and reinforced by the use of adjuvant cancer treatment [6]. It is well known that good preoperative cardiorespiratory capacity leads to better postoperative conditions resulting in less postoperative complications in patients with NSCLC $[1,5]$. Further studies are also warranted on other physical effects of exercise and how to commit this group of cancer patients to a more active lifestyle.

Studies focusing on the effects of exercise interventions pre- and postoperatively are required to fully understand the potential effect of exercise over time. The optimal 
characteristics of exercise (mode, intensity, frequency, duration, and timing) have yet to be determined [24].

No published research in cancer rehabilitation has investigated the best timing of rehabilitation in patients with NSCLC in a randomized clinical trial. Qualitative studies have pointed out that cancer patients may experience transition points during time of illness to which they are particularly vulnerable: (1) diagnosis, (2) operation and hospitalization, (3) transition from hospital to daily life, and (4) return to daily life [66-72]. The timing of rehabilitation has also been indicated to of importance when it comes to motivation toward a healthier life style in patients with a variety of cancer diagnoses [73]. The 'teachable moment' is a term used in e.g. research in breast cancer patients describing the transition that takes place when the patients are diagnosed. This transition can modify barriers and motivate the patient; thus timing of rehabilitation is of great importance for the outcome [74].

The PROLUCA study aims at revealing the impact of timing of rehabilitation on $\mathrm{VO}_{2}$ peak and healthpromoting behavior in patients with NSCLC. The effect six months and one year after surgery is measured. $\mathrm{VO}_{2}$ peak is chosen as the primary endpoint as this test provides the gold standard (direct) assessment of cardiorespiratory capacity [13]. In a hospital setting it would have been interesting to test cardiorespiratory capacity as early as two weeks postoperatively, but as the intervention in PROLUCA is carried out in a non-hospital setting, this is not possible due to safety reasons. According to the Danish Health Act from 2007 the responsibility for rehabilitation of all patients with a decrease in functional capacity lies with the municipalities unless medical assistance is needed. The same is true of patient-targeted prevention.

The patients perform a $\mathrm{VO}_{2}$ peak test preoperatively and again after the intervention. The first test acts as a surrogate parameter for the starting point, and PROLUCA is therefore not capable of clarifying what happens to $\mathrm{VO}_{2}$ peak shortly after surgery. Research indicates that $\mathrm{VO}_{2}$ peak spontaneously recovers to a limited degree at approximately 3 months after surgery and stabilizes at approximately 6 months after pulmonary resection. Another study finds a $13 \%$ decrease in $\mathrm{VO}_{2}$ peak $~ 6$ months after surgery [75]. As this study compares the preoperative $\mathrm{VO}_{2}$ peak with postoperative $\mathrm{VO}_{2}$ peak value 6 months after surgery, the best estimate possible is chosen.

To obtain a patient population as close to normal daily practice as possible where patients are suffering from a variety of comorbidity, PROLUCA limits the amount of exclusion criteria. This makes PROLUCA unique compared to other studies whose selection of patients is distinct. Therefore the results of PROLUCA may contribute importantly to daily clinical practice.
With the increasing interest in the field of exerciseoncology research, more studies are now focusing on the application of exercise as a concomitant intervention alongside anti-cancer therapies.

\section{Summary}

Even though rehabilitation, with focus on exercise, is widely recommended to cancer patients, information concerning timing and dose of exercise rehabilitation is lacking when it comes to patients operated for NSCLC. To our knowledge no previous studies have been published in which postoperative rehabilitation is initiated as early as two weeks after surgery for NSCLC. Furthermore, there is a distinct need for trials including NSCLC patients, since this group of patients is especially vulnerable due to a high burden of comorbidity, risk of relapse of the cancer disease and consequences of both surgical and oncological treatment. In addition, the patient population included in PROLUCA is as close to those seen in normal daily practice as possible. This makes PROLUCA unique compared to other studies whose selection of patients is distinct, and the results of the PROLUCA study may contribute importantly to daily clinical practice.

\begin{abstract}
Abbreviations
$\mathrm{VO}_{2}$ peak: Maximal oxygen uptake; NSCLC: Non-small cell lung carcinoma; HRmax: Heart rate max; 6 MWD: Six-minute walk distance; 1 RM: Onerepetition-maximum; PROs: Patient-reported outcomes; HRQoL: Health related quality of life; SCLC: Small-cell lung carcinoma; VATS: Video-assisted thoracoscopic surgery; TNM: Tumor node metastasis; ACSM: American College of Sports Medicine; EORTC: The European Organization for Research and Treatment in Cancer; FACT-L: Functional assessment of cancer therapy lung; SF-36: 36-item short form health survey; HADS: Hospital anxiety and depression scale; ATS: American Thoracic Society; FEV1: Forced expiratory volume in one second; FVC: Forced vital capacity; FEV $\%$ : Which is the ratio of $\mathrm{FEV}_{1}$ to the FVC.
\end{abstract}

\section{Competing interests}

The authors declare that they have no competing interests.

\section{Authors' contributions}

MSS: conception and design, drafting of manuscript and final approval for publication. KT: conception and design, drafting of manuscript and final approval for publication. JVP: conception and design, drafting of manuscript and final approval for publication. MM: conception and design and final approval for publication. MC: conception and design and final approval for publication. KRL: conception and design and final approval for publication. SWL: conception and design and final approval for publication. $\mathrm{CH}$ : conception and design and final approval for publication. PC: conception and design and final approval for publication. JHP: conception and design and final approval for publication. HL: conception and design and final approval for publication. All authors read and approved the final manuscript.

\section{Acknowledgements}

The study is supported by grants from The Center for Integrated Rehabilitation of Cancer patients (CIRE), a center established and supported by The Danish Cancer Society and The Novo Nordisk Foundation, and the study is supported by the Copenhagen University Hospital, the Faculty of Health Sciences, University of Copenhagen, and is secured by funding from The Municipality of Copenhagen. The authors thank Karl Bang Christensen, Associate professor, Department of Biostatics, University of Copenhagen, for his valuable assistance concerning biostatistics. 


\section{Author details}

${ }^{1}$ Copenhagen Centre for Cancer and Health, Municipality of Copenhagen, Nørre Allé 45, DK-2200 Copenhagen, Denmark. ²Department of Cardiothoracic Surgery RT, Copenhagen University Hospital (Rigshospitalet), Blegdamsvej 9, DK- 2100, Copenhagen, Denmark. ${ }^{3}$ Pulmonary Department L, Bispebjerg Hospital, University of Copenhagen, Bispebjerg Bakke 23, DK-2400 Copenhagen, Denmark. ${ }^{4}$ Department of Oncology, Copenhagen University Hospital (Rigshospitalet), Blegdamsvej 9, DK - 2100 Copenhagen, Denmark. ${ }^{5}$ Department of Public Health, Section of Social Medicine, Copenhagen University, Øster Farimagsgade 5, postbox 2099, DK-1014 Copenhagen, Denmark. ${ }^{6}$ Department of Pulmonary Medicine, Copenhagen University Hospital Gentofte, Niels Andersens Vej 65, DK-2900 Hellerup, Denmark. ${ }^{7}$ CopenRehab, Section of Social Medicine, Department of Public Health and Centre for Healthy Ageing, Faculty of Heath Sciences, University of Copenhagen, Copenhagen, Denmark.

Received: 10 July 2013 Accepted: 13 May 2014

Published: 4 June 2014

\section{References}

1. Storm HH, Engholm G, Hakulinen T, Tryggvadóttir L, Klint A, Gislum M, Kejs AMT, Bray F: Survival of patients diagnosed with cancer in the Nordic countries up to 1999-2003 followed to the end of 2006. A critical overview of the results. Acta Oncol 2010, 49:532-544.

2. Group DLC: Danish Lunge Cancer Group Annual Report 2011; 2011.

3. Fan G, Filipczak L, Chow E: Symptom clusters in cancer patients: a review of the literature. Curr Oncol 2007, 14:173-179.

4. Kenny PM, King MT, Viney RC, Boyer MJ, Pollicino CA, McLean JM, Fulham MJ, McCaughan BC: Quality of life and survival in the 2 years after surgery for non small-cell lung cancer. J Clin Oncol 2008, 26:233-241.

5. Lim E, Baldwin D, Beckles M, Duffy J, Entwisle J, Faivre-Finn C, Kerr K, Macfie A, McGuigan J, Padley S, Popat S, Screaton N, Snee M, Waller D, Warburton C, Win T: Guidelines on the radical management of patients with lung cancer. Thorax 2010, Suppl 3:1-27.

6. Jones LW, Eves ND, Haykowsky M, Freedland SJ, Mackey JR: Exercise intolerance in cancer and the role of exercise therapy to reverse dysfunction. Lancet Oncol 2009, 10:598-605.

7. Kavanagh T: Prediction of long-term prognosis in 12169 men referred for cardiac rehabilitation. Circulation 2002, 106:666-671.

8. Myers J, Prakash M, Froelicher V, Do D, Partington S, Atwood JE: Exercise capacity and mortality among men referred for exercise testing. $N$ Engl J Med 2002, 346:793-801.

9. Parsons A, Daley A, Begh R, Aveyard P: Influence of smoking cessation after diagnosis of early stage lung cancer on prognosis: systematic review of observational studies with meta-analysis. BMJ 2010, 340:b5569-b5569.

10. Neuenschwander AU, Pedersen $J H_{\text {, Krasnik M }}$, Tønnesen $\mathrm{H}$ : Impaired postoperative outcome in chronic alcohol abusers after curative resection for lung cancer. Eur J Cardiothorac Surg 2002, 22:287-291.

11. Suemitsu R, Takeo S, Hamatake M, Morokuma A, Suemori Y, Tanaka H: The results of surgery under general anesthesia in patients with lung cancer. Surg Today 2011, 41:60-66

12. Birim O, Kappetein AP, Bogers AJJC: Charlson comorbidity index as a predictor of long-term outcome after surgery for nonsmall cell lung cancer. Eur J Cardiothorac Surg 2005, 28:759-762

13. Jones LW, Eves ND, Kraus WE, Potti A, Crawford J, Blumenthal JA, Peterson $B L$, Douglas PS: The lung cancer exercise training study: a randomized trial of aerobic training, resistance training, or both in postsurgical lung cancer patients: rationale and design. BMC Cancer 2010, 10:155.

14. Steinberg T, Roseman M, Kasymjanova G, Dobson S, Lajeunesse L, Dajczman E, Kreisman H, MacDonald N, Agulnik J, Cohen V, Rosberger Z, Chasen M, Small D: Prevalence of emotional distress in newly diagnosed lung cancer patients. Support Care Cancer 2009, 17:1493-1497.

15. Carlson LE, Groff SL, Maciejewski O, Bultz BD: Screening for distress in lung and breast cancer outpatients: a randomized controlled trial. J Clin Oncol 2010, 28:4884-4891.

16. Graves KD, Arnold SM, Love CL, Kirsh KL, Moore PG, Passik SD: Distress screening in a multidisciplinary lung cancer clinic: prevalence and predictors of clinically significant distress. Lung Cancer 2007, 55:215-224.

17. Wildgaard K, Ravn J, Nikolajsen L, Jakobsen E, Jensen TS, Kehlet H: Consequences of persistent pain after lung cancer surgery: a nationwide questionnaire study. Acta Anaesthesiol Scand 2011, 55:60-68.
18. Jones K, Marie A: Rehabilitation needs of patients with lung cancer after surgery. Cancer Nursing Practice 2009, 8:23-28.

19. Carlsen $K$, Jensen $A B$, Jacobsen $E$, Krasnik M, Johansen C: Psychosocial aspects of lung cancer. Lung Cancer 2005, 47:293-300.

20. Maliski SL, Sarna L, Evangelista L, Padilla G: The aftermath of lung cancer. Cancer Nurs 2003, 26:237-244.

21. Handy JR, Asaph JW, Skokan L, Reed CE, Koh S, Brooks G, Douville EC, Tsen $A C$, Ott GY, Silvestri GA: What happens to patients undergoing lung cancer surgery? Outcomes and quality of life before and after surgery. Chest 2002, 122:21-30.

22. Sarna L, Cooley ME, Brown JK: Women with lung cancer: quality of life after thoracotomy. Cancer Nurs 2010, 33:85-92.

23. Balduyck B, Hendriks J, Sardari Nia P, Lauwers P, Van Schil P: Quality of life after lung cancer surgery: a review. Minerva Chir 2009, 64:655-663.

24. Si M, Rw S, Snyder C, Pm G, Topaloglu O: Exercise interventions on healthrelated quality of life for people with cancer during active treatment (Review) SUMMARY OF FINDINGS FOR THE MAIN COMPARISON; 2012.

25. Adamsen L, Quist M, Andersen C, Moller T, Herrstedt J, Kronborg D, Baadsgaard MT, Vistisen K, Midtgaard J, Christiansen B, Stage M, Kronborg MT, Rorth M: Effect of a multimodal high intensity exercise intervention in cancer patients undergoing chemotherapy: randomised controlled trial. BMJ 2009, 339:b3410-b3410

26. Granger CL, McDonald CF, Berney S, Chao C, Denehy L: Exercise intervention to improve exercise capacity and health related quality of life for patients with Non-small cell lung cancer: a systematic review. Lung Cancer 2011, 72:139-153.

27. Benzo R, Kelley GA, Recchi L, Hofman A, Sciurba F: Complications of lung resection and exercise capacity: a meta-analysis. Respir Med 2007, 101:1790-1797.

28. Zabora J, BrintzenhofeSzoc K, Curbow B, Hooker C, Piantadosi S: The prevalence of psychological distress by cancer site. Psychooncology 2001 10:19-28.

29. Doyle C, Kushi LH, Byers T, Courneya KS, Demark-Wahnefried W, Grant B, McTiernan A, Rock CL, Thompson C, Gansler T, Andrews KS: Nutrition and physical activity during and after cancer treatment: an American cance society guide for informed choices. CA Cancer J Clin 2006, 56:323-353.

30. Irwin ML: Physical activity interventions for cancer survivors. $\mathrm{Br} J$ Sports Med 2009, 43:32-38.

31. Holmes M, Chen W: Physical activity and survival after breast cancer diagnosis. JAMA 2005, 293:2479-2486

32. Meyerhardt JA, Heseltine D, Niedzwiecki D, Hollis D, Saltz LB, Mayer RJ, Thomas J, Nelson H, Whittom R, Hantel A, Schilsky RL, Fuchs CS: Impact of physical activity on cancer recurrence and survival in patients with stage III colon cancer: findings from CALGB 89803. J Clin Oncol 2006, 24:3535-3541.

33. Friedenreich CM, Gregory J, Kopciuk KA, Mackey JR, Courneya KS, Kopciuk KA, Mackey JR, Courneya KS: Prospective cohort study of lifetime physical activity and breast cancer survival. Int J Cancer 2009, 124:1954-1962.

34. Ballard-Barbash R, Friedenreich CM, Courneya KS, Siddiqi SM, McTiernan A, Alfano CM: Physical activity, biomarkers, and disease outcomes in cancer survivors: a systematic review. J Natl Cancer Inst 2012, 104:815-840.

35. Jones LW, Peddle CJ, Eves ND, Haykowsky MJ, Courneya KS, Mackey JR, Joy AA, Kumar V, Winton TW, Reiman T: Effects of presurgical exercise training on cardiorespiratory fitness among patients undergoing thoracic surgery for malignant lung lesions. Cancer 2007, 110:590-598.

36. Bobbio A, Chetta A, Ampollini L, Primomo GL, Internullo E, Carbognani $P$, Rusca M, Olivieri D: Preoperative pulmonary rehabilitation in patients undergoing lung resection for non-small cell lung cancer. Eur J Cardiothorac Surg 2008, 33:95-98.

37. Shannon VR: Role of pulmonary rehabilitation in the management of patients with lung cancer. Curr Opin Pulm Med 2010, 16:334-339.

38. Jones LW, Eves ND, Peterson BL, Garst J, Crawford J, West MJ, Mabe S, Harpole D, Kraus WE, Douglas PS: Safety and feasibility of aerobic training on cardiopulmonary function and quality of life in postsurgical nonsmall cell lung cancer patients: a pilot study. Cancer 2008, 113:3430-3439.

39. Jones LW, Eves ND, Spasojevic I, Wang F, Il'yasova D: Effects of aerobic training on oxidative status in postsurgical non-small cell lung cancer patients: a pilot study. Lung Cancer 2011, 72:45-51.

40. Riesenberg H, Lübbe AS: In-patient rehabilitation of lung cancer patientsa prospective study. Support Care Cancer 2010, 18:877-882

41. Spruit MA, Janssen PP, Willemsen SCP, Hochstenbag MMH, Wouters EFM: Exercise capacity before and after an 8-week multidisciplinary inpatient rehabilitation program in lung cancer patients: a pilot study. Lung Cancer 2006, 52:257-260. 
42. Cesario A, Ferri L, Galetta D, Pasqua F, Bonassi S, Clini E, Biscione G, Cardaci V, Di Toro S, Zarzana A, Margaritora S, Piraino A, Russo P, Sterzi S, Granone $P$ : Post-operative respiratory rehabilitation after lung resection for nonsmall cell lung cancer. Lung Cancer 2007, 57:175-180.

43. Arbane G, Tropman D, Jackson D, Garrod R: Evaluation of an early exercise intervention after thoracotomy for non-small cell lung cancer (NSCLC), effects on quality of life, muscle strength and exercise tolerance: randomised controlled trial. Lung Cancer 2011, 71:229-234.

44. Jones LW, Eves ND, Waner E, Joy AA: Exercise Therapy Across the Lung Cancer Continuum Corresponding author; 2009.

45. Rami-Porta R, Crowley JJ, Goldstraw P: The revised TNM staging system for lung cancer. Ann Thorac Cardiovasc Surg 2009, 15:4-9.

46. Sørensen JB, Klee M, Palshof T, Hansen HH: Performance status assessment in cancer patients. An inter-observer variability study. Br J Cancer 1993, 67:773-775.

47. Metkus TS, Baughman KL, Thompson PD: Exercise prescription and primary prevention of cardiovascular disease. Circulation 2010, 121:2601-4

48. Kreider ME, Grippi MA: Impact of the new ATS/ERS pulmonary function test interpretation guidelines. Respir Med 2007, 101:2336-2342

49. Boutron I, Moher D, Altman D, Schulz K, Ravaud P, Stephenson J, Consort G: Extending the CONSORT statement to randomized trials of nonpharmacologic treatment: explanation and elaboration. Ann Intern Med 2008, 148:295-309.

50. Garber CE, Blissmer B, Deschenes MR, Franklin BA, Lamonte MJ, Lee I-M, Nieman DC, Swain DP: American college of sports medicine position stand. Quantity and quality of exercise for developing and maintaining cardiorespiratory, musculoskeletal, and neuromotor fitness in apparently healthy adults: guidance for prescribing exercise. Med Sci Sports Exerc 2011, 43:1334-1359.

51. Ozdem $Y$, Inanici F, Hasçelik Z: Reduced vital capacity leads to exercise intolerance in patients with ankylosing spondylitis. Eur J Phys Rehabil Med 2011, 47:391-397.

52. Quist $M$, Rørth $M$, Langer $S$, Jones LW, Laursen JH, Pappot H, Christensen KB, Adamsen L: Safety and feasibility of a combined exercise intervention for inoperable lung cancer patients undergoing chemotherapy: a pilot study. Lung Cancer 2012, 75:203-208.

53. Aaronson N: The European organization for research and treatment of cancer QLQ-C30: a quality-of-life instrument for use in international clinical trials in oncology. J Natl Cancer Inst 1993, 85:365-376.

54. Bergman B, Aaronson NK, Ahmedzai S, Kaasa S, Sullivan M: The EORTC QLQ-LC13: a modular supplement to the EORTC core quality of life questionnaire (QLQ-C30) for use in lung cancer clinical trials. EORTC study group on quality of life. Eur J Cancer 1994, 30A:635-642.

55. Cella DF, Bonomi AE, Lloyd SR, Tulsky DS, Kaplan E, Bonomi P: Reliability and validity of the functional assessment of cancer therapy-lung (FACT-L) quality of life instrument. Lung Cancer 1995, 12:199-220.

56. Ware JE, Sherbourne CD: The MOS 36-item short-form health survey (SF-36). I. Conceptual framework and item selection. Med Care 1992, 30:473-483.

57. Fredheim OMS, Borchgrevink PC, Saltnes T, Kaasa S: Validation and comparison of the health-related quality-of-life instruments EORTC QLQC30 and SF-36 in assessment of patients with chronic nonmalignant pain. J Pain Symptom Manage 2007, 34:657-665.

58. Zigmond AS, Snaith RP: The hospital anxiety and depression scale. Acta Psychiatr Scand 1983, 67:361-370.

59. Bidstrup PE, Mertz BG, Dalton SO, Deltour I, Kroman N, Kehlet H, Rottmann N, Gärtner R, Mitchell AJ, Johansen C: Accuracy of the Danish version of the "distress thermometer". Psychooncology 2012, 21:436-443.

60. Pedersen SS, Spinder H, Erdman RA, Denollet J: Poor perceived social support in implantable cardioverter defibrillator (ICD) patients and their partners: cross-validation of the multidimensional scale of perceived social support. Psychosomatics 2009, 50:461-467.

61. Jarden M, Adamsen L, Kjeldsen L, Birgens H, Tolver A, Christensen JF, Stensen M, Sørensen V-A, Møller T: The emerging role of exercise and health counseling in patients with acute leukemia undergoing chemotherapy during outpatient management. Leuk Res 2013, 37:155-161.

62. Brooks D, Solway S, Gibbons WJ: ATS statement on six-minute walk test. Am J Respir Crit Care Med 2003, 167:1287.

63. Chuang ML, Lin IF, Wasserman K: The body weight-walking distance product as related to lung function, anaerobic threshold and peak VO2 in COPD patients. Respir Med 2001, 95:618-626.
64. Brzycki M: Strength testing: predicting a one-rep max from a reps-tofatigue. J Phys Educ Recr Dance 1993, 64:88-90.

65. Holm S: A simpel sequentially recejtive multiple test procedure. Scand J Statist 1997, 6:65-70.

66. Missel M, Birkelund R: Living with incurable oesophageal cancer. A phenomenological hermeneutical interpretation of patient stories. Eur $J$ Oncol Nurs 2011, 15:296-301.

67. Illingworth N, Forbat L, Hubbard G, Kearney N: The importance of relationships in the experience of cancer: a re-working of the policy ideal of the whole-systems approach. Eur J Oncol Nurs 2010, 14:23-28.

68. Lee $\mathrm{V}$ : The existential plight of cancer: meaning making as a concrete approach to the intangible search for meaning. Supportive Care Cancer 2008, 16:779-785

69. Sand L, Strang P: Existential loneliness in a palliative home care setting. J Palliat Med 2006, 9:1376-1387.

70. Sellman D: Towards an understanding of nursing as a response to human vulnerability. Nurs Philos 2005, 6:2-10.

71. Irurita VF, Williams AM: Balancing and compromising: nurses and patients preserving integrity of self and each other. Int I Nurs Stud 2001, 38:579-589.

72. Kåresen R, Langmark F: [Psychological, social and economic situation of women surgically treated for cancer]. Tidsskr Nor Laegeforen 2000, 120:2741-2748.

73. Stull VB, Snyder DC, Demark-Wahnefried W: Lifestyle interventions in cancer survivors: designing programs that meet the needs of this vulnerable and growing population. J Nutr 2007, 137:243S-248S.

74. Pinto BM, Maruyama NC, Clark MM, Cruess DG, Park E, Roberts M: Motivation to modify lifestyle risk behaviors in women treated for breast cancer. Mayo Clin Proc 2002, 77:122-129.

75. Larsen KR, Svendsen UG, Milman N, Brenøe J, Petersen BN: Cardiopulmonary function at rest and during exercise after resection for bronchial carcinoma. Ann Thorac Surg 1997, 64:960-964.

doi:10.1186/1471-2407-14-404

Cite this article as: Sommer et al:: Perioperative rehabilitation in operation for lung cancer (PROLUCA) - rationale and design. BMC Cancer 2014 14:404.

\section{Submit your next manuscript to BioMed Central and take full advantage of:}

- Convenient online submission

- Thorough peer review

- No space constraints or color figure charges

- Immediate publication on acceptance

- Inclusion in PubMed, CAS, Scopus and Google Scholar

- Research which is freely available for redistribution

Submit your manuscript at www.biomedcentral.com/submit
C) BioMed Central 